\title{
ANNOTATION
}

\section{The Care of the Blind in Scotland}

The Scottish Advisory Committee on the Welfare of the Blind has just issued its fourth report covering the years 1926-1927. They note that progress in the administration of the Blind Persons Act is being well maintained. Further, that there are certain areas in Scotland from which appeals are seldom received by the Board in connection with claims to pensions under this Act, and that these areas are those in which the arrangements of Outdoor Societies for the medical certification of blind persons are most efficient and where close co-operation exists between the Societies and the Pension officers in regard to certificates of blindness. Grants-inaid to valuable training institutes have been made by certain local authorities. Thus the combination of councils in the south-west of Scotland has incurred expenditure amounting to about $£ 25,000$ in the purchase and equipment of a factory in the Possilpark district of Glasgow as an extension of the Royal Glasgow Asylum for the Blind.

The Central Register of the Blind shows a steady, though not a large, increase. This is in the main due to the more active interest taken in blind matters by local authorities, the increased activity of voluntary agencies, and the granting of old-age pensions to the blind.

The decrease, mentioned in the last Report in the number of children of and under school age, we are pleased to note, has been maintained. The Committee express their belief that this decrease is due to a considerable extent to the measures adopted by local authorities for the prevention and treatment of disease, particularly the measures taken for the prevention and treatment of ophthalmia neonatorum and venereal diseases, and the extending provision made under maternity and child welfare schemes. In a Utopia of the future we feel that blindness at the school age will be an indictable offence.

The Report deals with methods of technical education, the possible absorption of the blind into various industries, and their treatment in other countries: it does not favour the compulsory notification of blindness. It is a business-like document and gives an account of a well-organized system. 